\title{
Re-texting as Translation: A Study Based on Ramayana Translations in India
}

\author{
Sreedevi K. Nair
}

\begin{abstract}
The purpose of this article is twofold. The first is to draw attention to a category of texts like Sita Dukham which position themselves between original texts and translations - just below original creations and much above translations (translation is used here in its restricted sense of linguistic transfer). The second is to analyze the process of re-texting which results in the formation of such texts, to establish the validity of this process and to mark its contours. The article is consequently organized in two parts. The first part fixes the context of the study and details the special aspects of the selected text, namely Sita Dukham. The second section discusses the process of re-texting.
\end{abstract}

\section{The Context of the Study and Sita Dukham}

The literary tradition of Malayalam as well as all the other Indian languages is replete with creative retellings of ancient literature. The Ramayana and The Mahabharata are the two Indian master narratives that have been rendered into a multiplicity of languages and in a variety of ways, down the centuries. Such intracultural rewritings stem from an ideology which recognizes the parity of the source and the target languages; the source culture and the target culture; the original author and the translator; the source text and the rewritten text; the creative talent of the author and the individual preferences as well as uniqueness of perceptions of the translator; the genius of the source language and the specificities of the target language. There is, in such cases, no dominant cultural discourse or any assumption of textual essentialism, no dislocated centre or margin. What exists in the 
practice is only an open recognition of plurality and difference within cultures. For example, though Valmiki Ramayana is considered to be the Aadi Kaavya ${ }^{2}$ or the first poem, each region in India has its own version of the epic which holds sway over the mind and imagination of the people there. Such regional versions which teem with local imagery, customs and ways are known by the name of the translator and not by the name of the original writer. Thus, Kerala has Ezhuthacchan ${ }^{3}$ Ramayana, Tamil Nadu has Kamba $a^{4}$ Ramayana, the Hindi-speaking northern states have Tulsis Ramayana (also called the Ramacharit Manas) and so on - Ezhuthacchan, Kamban and Tulsi referring to respective translators.

The text chosen in this article for case study is Sita Dukham, a short, simple narrative written in the early decades of eighteenth century in Kerala. The work is largely 'original' though the outline of the story, the characters and the major incidents remain almost the same as in many earlier texts. The writer hasn't made major changes to the framework of the story but has made very skilful and artistic twists and turns to rewrite it. No new characters are created either only fresh dimensions are added to existing characters. Thus Sita Dukham which runs to just a few pages only, re-writes the original to present yet another version of it which reads refreshingly original.

Some of the significant changes made in Sita Dukham are the following. The whole long section of Uttara Ramayana ${ }^{6}$, i.e. the latter half of the Ramayana is compressed into eleven and a half pages. In the original Ramayana, the king's messenger brings the news that Rama's subjects suspect the chastity of Sita who has for several months lived in the kingdom of Ravana and that compels Rama to abandon his wife in the forest. In Sita Dukham, it is the ploy of her mother-in-law that gets Sita into trouble. When Rama is gone hunting, the uncles -in-law make Sita draw the imposing image of Ravana on a wooden seat. Sita sketches the glorious tenheaded Ravana - one of his faces chanting the Vedas, another enjoying music, yet another face meditating on Sita, another face challenging the Sun God, so on and so forth and the mammas-in- 
law revel looking at it but when Rama comes, they purposefully give him that very seat to sit on. When he sits on it, the picture of Ravana shirks him off. Rama looks to see what is wrong and sees the gorgeous image of Ravana staring back. Then the Mammas-inlaw narrate to him how Sita entertains herself regularly by drawing pictures of Ravana. Enraged at this, Rama asks his younger brother Lakshmana to take Sita to the forest and to kill her.

Secondly, when Lakshmana comes back supposedly after doing the deed, the Mammas-in-law insist on seeing Sita's blood in the sword. This is unthinkable from the part of the noble mother-in-laws figuring in the original. In Sita Dukham however, when Lakshmana produces his sword smeared with the blood of python, they send him off to the forest saying they can distinguish animal and human blood; a second time they tell him that they can identify male and female blood. So the third time, Lakshmana returns to the forest, cuts off Sita's finger and stains his sword with her very blood.

Another interesting change is also introduced in the narration of the birth of Sita's twin boys. In the original, Sita who was five months into pregnancy at the time of her abandonment, gives birth to twin boys, Lava and Kusa. In Sita Dukham, Sita gives birth only to Lava. One day, she goes to pluck flowers for the evening rites leaving her little one with the Valmiki. But the child moves away and goes to his mother without the sage noticing. The sage could not find him anywhere and so creates his likeness from a blade of grass and breathes life into the form. Thus he becomes Kusa - Kusa being the name of the grass from which he was created.

Thus there are various alterations in this eleven and a half page story and the old story is retold from a very different perspective. This marvelously transforms the story. It is like looking at the same mountain from a different angle of vision -the whole appearance, the stature and the elegance, the pinnacles touching the sky, the foam-like clouds floating around and even the play of light and shade on the peaks, alter and change. It is the same 
mountains in the very same setting but an amazing transformation of view occurs.

Several other interesting alterations assure Sita Dukham a rightful place as an original text. Besides, not even a single sentence in Sita Dukham is a faithful rendering of any original text. Each and every sentence thus being 'original', the work cannot be termed a translation in the conventional sense of the term. At the same time, the story, the characters and the plot being largely borrowed, the book is unfit to be regarded a full-fledged original either. The making of such an 'original' text from an existing source text or a multiplicity of texts built around the same story, involves a complex process almost similar to the creation of a new text. The central event or the frame work of the story is all that is borrowed while all or most of the textual elements and procedures are new or are transformed drastically. What occurs during the process is not simply translating but re-texting which facilitates presentation of familiar matter using novel textual features and texting techniques. The works thus created claim an independent space and stature in the target language and culture. Very often, they turn out to be intra-cultural textual negotiations which enjoy parallel existence vis-à-vis their source texts.

\section{Re-Texts (Re-Texted Texts) \& the Process of Re-Texting}

Re-texting is a case of translation which involves a complex process of re-creating one or more original texts or selected parts of them to produce a Target Text which enjoys sovereign existence in the target language. The Source in re-texting need not necessarily be a single text. Several Sources, popular notions and ideas surrounding Source texts, cultural, social and historical significances read into it - all these together form the composite corpus received and handled by the translator. Thus, instead of a single source text, there is Source Composite in re-texting. The Source Composite acts as a kind of Seed Text from which Re-Texts stem forth.

\section{The Concept of the Seed Text}


Shelley says in his Defence of Poetry, 'The plant must spring again from its seed, Or it will bear no flower.' As plants grow from seeds, so do Re-Texts from Seed Texts. The Seed Text is the assortment of embryonic details selected by subsequent authors from canonical originals to create new texts which share storylines, themes, characters and maybe ideas but are original and unique in themselves. The Seed Text acts as the nucleus around which the new text takes shape. Details, emotions, specificities which best befit the purposes of the author are added; his imagination works on it, his words give expression and a new text gets formed. The adding, deleting, mixing and moulding processes set in motion a series of new meanings and as the new text takes form they reach a fresh equilibrium.

Accepting just a bunch of bare details provides immense scope for writing new. The plot and the setting are partially retained but most other textual features get transformed in a major way. Partially retained plot and setting, constitute the Seed Text which each writer develops into more or less a new text, unique in form, diction, thought and action. This phenomenon of subsequent texts relating to prior texts in differing ways and maintaining relationships among themselves was referred to by Ramanujan in his article titled 'Three Hundred Ramayanas' included in Many Ramayanas edited by Richman . Ramanujan likens the Ramayana tradition to a pool of signifiers that include plot, setting, characters and the like and says that each new Ramayana is a 'crystallization' created out of it. He says,

'These various texts not only relate to prior texts directly, to borrow or refute but they relate to each other through this common code or common pool. Every author, if one may hazard a metaphor, dips into it and brings out a unique crystallization, a new text with a unique texture and a fresh context.' (p. 46)

The metaphor of the pool of signifiers is beautiful and telling but crystallization is not a culmination point beyond which moving is frozen. Generations of subsequent texts can result from such crystallizations which may all share similarities among 
themselves.

The Seed Texts provide a grid with a number of evocative gaps and suggestive silences. The way the gaps and silences get worked upon, decides the nature of the new text. Seed Texts of the same story selected by different authors need not correspond with each other. From the hundreds of versions of a story that are extant, each writer accepts a bunch of details full of possibilities and potentialities and suited particularly to his purpose. This serves as the Seed Text for his narration. Just as the multitudinous seeds of a tree carrying inherited similarities grow out to sport different forms and figures under new skies, under different climatic conditions and in new growing mediums, the seed texts branch out to fresh textual formations which relate backwards to prior texts in some way and forwards to possible future texts. Endless generations of Re-Texts thus become possible.

\section{Re-Texting: A Western Example}

The case of Milton's Paradise Lost can be cited as an example of Re-texting. For the central event described in Paradise Lost, Milton's authority is the first few chapters of the 'Genesis'. For the rest, he draws freely upon the Old Testament as well as legends and stories that have accumulated round the biblical story which act as his Source Composite. However, for most of the elaborations, his mainstay is his own power of imagination. The original which is a few pages of The Bible thus swells to the proportions of an epic of twelve books.

Alteration of text as well as texting techniques transforms the work completely. The language of The Bible which is a kind of poetic prose turns to pure poetry in the target text. The structure of Paradise Lost and the arrangement of events too are Milton's. He begins the story in the middle. In Book 1, Satan rises with Beelzebub from the burning lake of Hell where he has been cast. He rouses his stupefied legions, tells them of Earth and its new inhabitants and exhorts them to fresh efforts against the Almighty. The story of the creation of the world with which 
Re-texting as Translation: A Study Based on Ramayana Translations in India

the 'Genesis' opens, is described much later in Book 7. What is more striking is the way Milton infuses the biblical story with his personal feelings. There is a strange analogy between the author and Satan. This makes him put into the mouth of Satan some of the most passionately lyrical passages in the poem. Like Milton, Satan too is a rebel. He too had known a mighty past, had dreamt beautiful dreams and reached with all his might for a great venture. He lost miserably but struggled on valiant and undismayed against hopeless odds. Milton who carved Satan in his own likeness invested him surreptitiously with such noble traits that he turns out to be a splendidly lovable criminal and the very hero of Paradise Lost. The work which was written to 'justify the ways of God to men', ultimately ends up glorifying Satan. Thus, in Re-texting the translator ceases to be a faithful transmitter of the author's meaning and becomes the co-creator of the new text in every sense. The relationship between the original and the target text very often develop into a two way alliance in which each work upon the other, transform and get transformed reciprocally. The case of Paradise Lost exemplifies the phenomenon. Critics point out that many people attribute to the details of the Bible, which do not figure in the Holy Book at all. In his introduction to Milton's Paradise Lost, D.C. Somerveli says, 'The narrative of Paradise Lost has itself become a part of our popular tradition and probably many a man attribute to The Bible itself details that belong only to Milton.' Such reciprocity is a characteristic feature of re-texted works.

The practice of Re-texting allows the translator to add, delete, subvert, critique or transform text/ textual elements. Such enormous freedom becomes possible as the unit of translation is not words, sentences or even larger textual components. The unit of translation in re-texting is the whole text which renders itself to revision, reinterpretation and re-creating. Hence, conventional yardsticks for judging translation such as faithfulness to the original or the creation of equivalent effect cannot be applied for re-texted works. What is aimed at through re-texting is not the production of a text 'equivalent' to the Source Text but the 
creation of a parallel text of autonomous standing in the target language and culture. The worth or worthlessness of the retexted text is judged irrespective of its allegiance to the source. Re-texting is possible not only in the case of classical or legendary literature but also modern literature and it could be intra-lingual or interlingual.

\section{A Case for Re-texts}

This newly identified category of in-between texts (between original texts and translations) can best be termed $\boldsymbol{R} \boldsymbol{e}$ Texts - i.e. Re-Texted texts. The name Re-Text is self-explanatory. At one level, it is the re-presentation of a text. At another, it is a re-textable text -i.e., a text which functions like any other text and can lend itself to further translation or re-texting and thus get represented as a fresh Text. A Re-Text is the creative reconstruction of a source text produced through the process of re-texting which involves re-interpretation, re-ordering and re-writing of the original. They enjoy parallel existence vis-à-vis their source/ sources and receive praise or blame as any original text in the target language. Epics in general are many dimensional magic canvases which afford myriad views at the touch of an inspired hand. The moment the canvas is so adjusted that a particular character or incident is centered, all the other characters move as in a fluid medium and the whole picture gets re-adjusted to project a new structuration. The canvas and the forms and figures in it remain age-old but the picture, color, value, texture and formation will be new. The newly projected pictures though original, will be a pointer to all those myriad pictures that flashed and faded off in the past; they also lend a hazy view of the many possible pictures that may come alive in the future at the ingenious stroke of yet another mastermind. Same canvas, same setting, same characters yet countless new visions and texts!

Mona Bakerwrites in her introduction ,'One of the most fascinating things about exploring the history of translation is that it reveals how narrow and restrictive we have been in defining our object of study, even with the most flexible of definitions.' The 
Re-texting as Translation: A Study Based on Ramayana Translations in India

creation of the terms $\boldsymbol{R}$ e-Texts and $\boldsymbol{R e}$-texting are necessitated by this predicament. Re-texted works positioned very close to original writings and leading a parallel existence in the target language and culture deserve a name and in-depth study. The case of texts like Sita Dukham and Paradise Lost is not an isolated one. There are treasured, Re-texted classics in all the languages. They remain invisible for lack of an individuating name. As texts that owe their existence to previous texts, they merit a place in the broad spectrum of translations, more specifically so among intracultural translations.

\section{NOTES}

1. A celebrated poet in Sanskrit Literature who wrote the epic Ramayana.

2. Works supposed to be the first literature in Sanskrit.

3. Thunchaththu Ramanujan Ezhuthachan- a Malayalam devotional poet and linguist from around the 16th century, also known as the father of Malayalam language

4. Kamban/ Kambar - a medieval Tamil poet and the author of the Ramavataram, the Tamil version of Ramayana.

5. Goswami Tulsidas - a Hindu poet-saint, reformer and philosopher.

6. The Uttara kanda/ Uttara Ramayana comprises of a later addition to Valmiki Ramayana which mostly concerns about the final years of Rama, Sita, and Rama's brothers.

\section{REFERENCES}

Baker, Mona \& Saldanha, Gabriela. 2009. Routledge Encyclopedia of Translation Studies. New York: Routledge, 2009.

Richman, Paula. 1991. Many Rāmāyaṇas: The Diversity of a Narrative Tradition in South Asia, California: The Regents of the University of California, 1991.

Somerveli, D.C. 1920. John Milton's Paradise Lost, London: J.M.Dent and Sons Ltd, 1920. 